\title{
EDUCAÇÃO DO CAMPO COMO UM PROCESSO DE RESISTÊNCIA: a experiência do PRONERA na Universidade Estadual Vale do Acaraú, estado do Ceará
}

\author{
EDUCACIÓN DEL CAMPO COMO UN PROCESO DE \\ RESISTENCIA: la experiencia del PRONERA en la Universidad \\ Estatal Vale do Acaraú, estado del Ceará
}

\author{
Aldiva Sales Diniz \\ Universidade Estadual Vale do Acaraú - Pós-Graduação em Geografia, \\ Sobral CE, Brasil \\ aldivadiniz@gmail.com
}

\section{Resumo}

Este artigo traz considerações acerca da Educação do Campo a partir de uma experiência do Programa Nacional de Educação na Reforma Agrária (PRONERA) vinculado ao recém extinto Ministério do Desenvolvimento Agrário (MDA). Inicialmente apresentamos um rápido resgate histórico da luta pela Educação do Campo, em seguida expomos as experiências de dois programas realizados na Universidade Estadual Vale do Acaraú, em Sobral, Estado do Ceará. A primeira experiência foi realizada através de um curso de educação voltado para jovens e adultos nas áreas de Assentamentos de Reforma Agrária. Este curso aconteceu com 73 turmas de alfabetização de Jovens e adultos em 42 Assentamentos de Reforma Agrária na Região Norte do Ceará. A segunda experiência se deu através de um Curso de Segunda nas Áreas de Ciências Humanas e Sociais: (Licenciatura em Geografia; Licenciatura em História); com o objetivo de habilitar professores e professoras e outros profissionais da educação com formação inicial em pedagogia ou em outra licenciatura que estivessem morando em áreas de Assentamentos de Reforma Agrária.

Palavras-chave: Educação do Campo. PRONERA. Movimentos sociais camponeses.

\section{Resumen}

Este artículo trae consideraciones acerca de la Educación del Campo a partir de una experiencia del Programa Nacional de Educación en la Reforma Agraria (PRONERA) vinculado al recién extinguido Ministerio del Desarrollo Agrario - MDA. Inicialmente presentamos un rápido rescate histórico de la lucha por la Educación del Campo, a continuación exponemos las experiencias de dos programas realizados en la Universidad Estatal Vale do Acaraú, en Sobral, Estado de Ceará. La primera experiencia fue realizada a través de un curso de educación dirigido a jóvenes y adultos en las áreas de Asentamientos de Reforma Agraria. Este curso ocurrió con 73 grupos de alfabetización de Jóvenes y Adultos en 42 Asentamientos de Reforma Agraria en la Región Norte de Ceará. La segunda experiencia se dio a través de un Curso de Segunda Licenciatura en las Áreas de Ciencias Humanas y Sociales: (Licenciatura en Geografía, Licenciatura en 
Historia); con el objetivo de habilitar profesores y profesoras y otros profesionales de la educación con formación inicial en pedagogía o en otra licenciatura que estuviesen viviendo en áreas de Asentamientos de Reforma Agraria.

Palabras clave: Educación del Campo. PRONERA. Movimientos sociales campesinos.

\section{Introdução}

Este artigo apresenta algumas reflexões acerca da Educação do Campo a partir de duas experiências do Programa Nacional de Educação na Reforma Agrária (PRONERA) realizado na Universidade Estadual Vale do Acaraú. Em primeiro lugar falamos do contexto da Educação do Campo, pois esta se configura enquanto um processo em construção, voltando-se para fortalecimento da identidade camponesa, bem como para a afirmação do campo enquanto espaço de trabalho e de vida.

O PRONERA é um dos agentes fortalecedores dessa proposta. Esse projeto inicialmente tinha como objetivo a redução da taxa de analfabetismo, hoje já possui cursos de formação de professores nos níveis superior e médio, um mestrado acadêmico e habilitação técnico-profissional, para jovens e adultos, seguindo a linha de interesse para a formação na área de produção, agropecuária, entre outras.

Em um segundo momento, relatamos e analisamos as duas experiências que aconteceram na Universidade Estadual Vale do Acaraú - UVA. A primeira experiência foi realizada com turmas de alfabetização de Jovens e adultos em 42 Assentamentos de Reforma Agrária com um total de 73 turmas, perfazendo um total de 1.460 jovens e adultos. A segunda experiência foi a realização de um curso de Segunda Licenciatura nas Áreas de Ciências Humanas e Sociais, Licenciatura em Geografia e Licenciatura em História. Este tinha como objetivo habilitar professores(as) e outros profissionais da educação com formação inicial em pedagogia ou em outra licenciatura que estivessem morando em áreas de Assentamentos de Reforma Agrária.

Como etapa final do artigo, concluímos mostrando a importância e o alcance social dessa política para os agricultores e agricultoras, pois a Educação do Campo traz, consigo, uma série de valores e práticas que buscam uma valorização do modo de vida camponês, estando assim dentro do paradigma de interpretação da revalorização do campo. Aqui apresentamos, também, alguns desafios a serem enfrentados com a atual conjuntura política a qual coloca em risco não somente as conquistas dos camponeses e camponesas, mas a própria democracia brasileira. 


\section{Procedimentos Metodológicos}

Este artigo tem como base o relato de duas experiências realizadas na Universidade Estadual Vale do Acaraú através do Programa Nacional de Educação na Reforma Agrária (PRONERA).

As duas experiências resultaram de uma demanda dos movimentos sociais campesinos. Os beneficiários foram os assentados e assentadas das áreas de Assentamento de Reforma Agrária reconhecidas pelo INCRA- Instituto Nacional de Colonização e Reforma Agrária.

A primeira experiência aconteceu entre os anos 1998 e 2002, com um projeto de Educação de Jovens e adultos que alfabetizou 1.460 jovens assentados. Para iniciar o curso os movimentos sociais escolheram 73 assentados e assentados que passaram por um processo de formação ministrado em quatro encontros perfazendo um total de 240 horas/aula. Estes, ao lado das suas atividades agrícolas, assumiram a tarefa de alfabetizadores(as) e passaram a ser chamados(as) de monitores, foram os principais atores do processo de alfabetização, pois estiveram diretamente envolvidos com os alunos e alunas aplicando a metodologia proposta.

Para ajudar no processo de acompanhamento de sala de aula foram selecionados 10 estudantes universitários dos cursos de Geografia, História e Pedagogia que ficaram encarregados de acompanhar as salas de aula tendo como tarefa identificar as dificuldades na implementação do projeto. Estes passaram a ser chamados de Coordenadores Locais. Cada Coordenador ficou encarregado de acompanhar 10 turmas e também passaram pelo mesmo processo de formação junto aos Monitores.

As turmas, em um total de 73 , foram formadas com um total de 20 alunos por sala perfazendo um tempo total de alfabetização de $560 \mathrm{~h} / \mathrm{a}$. Para conciliar as aulas com as atividades diárias dos alunos e alunas, foram ministradas duas horas/aula todos os dias da semana, totalizando 14 meses de aula. As aulas foram ministradas das 19:00 às 21:00 horas.

A segunda experiência teve duração de dois anos, começado a ser executado em 2015 e finalizado em 2017, o objetivo foi formar duas (02) turmas de Licenciatura em Ciências Humanas e Sociais, através dos Cursos de Geografia e História com vagas destinadas para a região Nordeste. A construção da matriz curricular se deu em diálogo da Universidade com o Movimento dos Sem Terra -MST, as Secretarias Municipais da região, a Secretaria da Educação do Ceará -SEDUC e o Comitê Executivo da Educação 
do Campo do Estado do Ceará.

Os(as) Candidatos(as) que participaram do processo de seleção do curso foram mobilizados pelo MST e as organizações locais o qual estavam inseridos, os critérios para participarem da seleção foi: participação na vida da comunidade; Engajamento nos Movimentos Sociais e em processos de educação; Formação e organização nos Assentamentos de Reforma Agrária. Nessa perspectiva, após a organização da demanda feita pelo Movimento, houve a inscrição dos candidatos para a realização da seleção pela Universidade.

O curso foi organizado e concebido a partir da formação em alternância, ou seja, com um ritmo de organização de formação em sequências de alternâncias. Nessa lógica, a alternância é compreendida e efetivada de forma integrativa na formação, constando do Tempo Universidade (TU) e o Tempo Comunidade (TC). O Tempo Universidade destinado a formação presencial no campus universitário da UVA O Tempo Comunidade destinado à pesquisa e as práticas e vivências, dedicado às pesquisas e aplicações, buscando intervir, melhorar e transformar as práticas.

\section{O PRONERA no Contexto da Educação do Campo}

O Programa Nacional de Educação na Reforma Agrária - PRONERA surgiu em 1998, fruto da luta dos movimentos sociais do campo pelo direito de acesso à educação pública de qualidade, e na busca do acesso aos povos do campo à própria educação, direito esse que foi historicamente negado

Nesse sentido, os movimentos sociais do campo, em especial o Movimento dos Sem Terra - MST discutem a problemática da educação, considerando a necessidade de existência de uma nova proposta de educação voltada para suas especificidades. Assim sendo, esse movimento, além da luta pelo acesso à terra, passa a pautar também a luta pela educação, na compreensão de que a luta pela terra perpassa pela luta por uma educação e escolarização para uma população historicamente excluída das políticas públicas. Nessa perspectiva, Souza (2013) analisa que:

A complexidade que a luta pela terra adquiriu na contemporaneidade colocou novos desafios aos movimentos sociais, fazendo-se necessário buscar novas formas de resistência. A própria estrutura das organizações se complexificou para dar conta dos novos desafios. Essa complexificação provocou a necessidade da preparação dos trabalhadores e de suas organizações, fazendo com que entrasse em pauta a luta pelo acesso ao conhecimento. Esses deixaram 
de lado a condição de isolamento, e nas ruas passaram a ser instituidores de políticas. (SOUZA, p. 20 2013).

A luta do MST é uma luta para o desenvolvimento do campo e a educação desempenha um papel estratégico no processo de sua construção e implementação. Respeitando a diversidade dos sujeitos e defendendo o campo como um lugar de vida, cultura, produção, moradia, educação, lazer com o olhar sempre voltado para a especificidade social, cultural e ambiental dos sujeitos. A educação desses diferentes grupos tem especificidades que devem ser respeitadas e incorporadas nas políticas públicas e no Projeto Político-Pedagógico da Educação do Campo.

É nessa compreensão que os movimentos têm pautado a luta pela Educação do Campo como sendo necessária para um projeto de reforma agrária. Tal luta faz parte da pauta da Educação do Campo, na perspectiva de criação de políticas públicas voltadas para a alfabetização de jovens e adultos, até políticas que garantam a elevação de escolaridade desses sujeitos.

Foi nesse contexto de luta que surgiu o PRONERA, em 16 de abril de 1998. O programa foi criado por meio da portaria $\mathrm{N}^{\circ} 10 / 1998$, publicada pelo então Ministério Extraordinário da Política Fundiária e, foi ratificado como política pública pelo Decreto $\mathrm{N}^{\circ} 7.352$ de 4 de novembro de 2010. Constitui-se como uma parceria entre o Instituto Nacional de Colonização e Reforma Agrária - INCRA, as universidades e os movimentos social e sindical do campo.

O PRONERA tem como público-alvo jovens e adultos moradores em Assentamentos da Reforma. Conforme já analisou Diniz (2002/2003), este Programa foi uma resposta às demandas sociais por educação, a partir da constatação revelada pelo I Censo da Reforma Agrária do Brasil realizado em 1996, que mostrou a baixa escolaridade dos assentados e assentadas:

\footnotetext{
A escolaridade nos assentamentos de Reforma Agrária é baixa e há um alto índice de analfabetismo, chegando em alguns Estados a 70\% e registrando uma média nacional de $45 \%$, ou seja, o percentual de analfabetos nos assentamentos rurais do país é maior que a média do país. Estas altas taxas de analfabetismo no meio rural acontecem devido uma série de fatores, como: dificuldades de acesso às escolas (estradas precárias), necessidade das crianças em ajudar os pais nas tarefas diárias nas propriedades, distâncias das propriedades até as escolas. Os índices de analfabetismo no meio rural brasileiro, permanecendo nos níveis em que se encontram, podem ser um forte obstáculo à viabilização da Reforma Agrária no país. Na maioria dos casos o ensino que é oferecido à população rural é o mesmo que é dado a população urbana, nem sempre sendo o mais adequado a quem mora no campo, visto que o contexto é diferente no que diz respeito a valores e cultura. (INEP/ I PNERA 2005).
} 
Neste sentido, a luta pela conquista do referido Programa busca desenvolver um projeto de Educação do Campo que reconhece o saber popular, que valorize o conhecimento dos educandos e leve em consideração as especificidades do campo, como exposto abaixo:

\begin{abstract}
A educação do campo deve ser uma educação que assuma a identidade do meio rural, não só como uma cultura diferenciada, mas como um contexto em que se efetive um projeto de desenvolvimento do campo, ou seja, uma escola do campo comprometida com um projeto político-pedagógico vinculado às causas, aos desafios, aos sonhos, à história e à cultura de quem vive e trabalha no campo. (MORIGI 2003: 24).
\end{abstract}

Conforme nos lembrou Vendramini, (2017) é preciso compreender que a Educação do Campo não emerge no vazio e nem é iniciativa das políticas públicas, mas emerge de um movimento social, da mobilização dos movimentos sociais campesinos, da luta social.

Nesse sentido, a Educação do Campo surgiu para se contrapor ao modelo de educação rural que ainda hoje persiste no campo brasileiro. No processo educativo oficial, sempre tivemos uma educação rural reprodutora/domesticadora que objetiva formar para a submissão, preparando mão-de-obra barata para o capital urbano e para o agronegócio, reproduzindo as relações sociais vigentes que são, por sua vez, excludentes. Daí a necessidade de construção de outro modelo de educação para os povos do campo, de uma nova visão acerca do ensino no campo, tendo em vista a necessidade de superação de um preconceito, ideologicamente formalizado, de que a educação para os povos do campo não precisa ser de boa qualidade, bastando às "primeiras letras". Esta ideologia foi concebida a partir do discurso dominante de que o camponês não necessita de saber ler, escrever, pensar ou refletir. É, pois, este pensamento que domina os governos e a própria produção acadêmica. Neste sentido, Arroyo (2004) acrescenta:

[...] A imagem que sempre temos na academia, na política, nos governos é que para a escolinha rural qualquer coisa serve. Para mexer com a enxada não há necessidades de muitas letras. Para sobreviver com uns trocados, para não levar manta na feira, não há necessidade de muitas letras. Em nossa história domina a imagem de que a escola no campo tem que ser apenas a escolinha rural das primeiras letras. A escolinha cai não cai, onde uma professora que quase não sabe ler ensina alguém a não saber quase ler. (ARROYO, 2004, p.71).

Assim sendo, as propostas de educação para as áreas de Assentamentos e acampamentos, expostas nos documentos produzidos pelo MST, como também as experiências pedagógicas desenvolvidas nas escolas acompanhadas por este Movimento, mostraram que é possível a realização de uma educação que pudesse abandonar o modelo 
de ensino rural, incompatível com a idéia de transformação da sociedade, defendida pelos ideais do Movimento. Uma Educação "que seja no e do campo. No: o povo tem direito a ser educado no lugar onde vive; Do: o povo tem direito a uma educação pensada desde o seu lugar e com a sua participação, vinculada à sua cultura e às suas necessidades humanas e sociais". Assim, CALDART (2002) considera que:

\begin{abstract}
Não se trata de propor algum modelo pedagógico para as escolas do campo, mas sim de construir coletivamente algumas referências para processos pedagógicos a serem desenvolvidos pela escola, e que permitam que ela seja obra e identidade dos sujeitos que ajuda a formar, com traços que a identifiquem com o projeto político e pedagógico da Educação do Campo. (CALDART, 2002 p-26).
\end{abstract}

Ela parte das experiências dos movimentos sociais que têm como principal fundamento a relação da teoria com a prática, ou seja, da luta cotidiana pela transformação da sociedade e que, para isso, exige que esta educação seja pensada a partir destes sujeitos e de onde eles se inserem socialmente. Por isso, conforme afirma Caldart (2012), a educação do campo combina luta pela educação com luta pela terra, pela Reforma Agrária, pelo direito ao trabalho, à cultura, à soberania alimentar, ao território

A discussão da Educação do Campo surge nesse cenário de intensas lutas. Tem como marco o I Encontro Nacional dos Educadores/as da Reforma Agrária - I ENERA, em 1997, no período de 27 a 31 de julho de 1997, em Luziânia - GO, onde foram discutidas as várias experiências educacionais realizadas nas diversas áreas de reforma agrária do país:

\begin{abstract}
Nesse encontro estiveram presentes, entre outros, movimentos sociais e entidades como a Conferência Nacional dos Bispos do Brasil - CNBB, Fundo das Nações Unidas para a Infância - UNICEF, Organização das Nações Unidas para a Educação, a Ciência e a Cultura - UNESCO e a Universidade de Brasília - UNB, com o intuito de ampliar as discussões sobre a educação no meio rural.A educação do campo deve ser uma educação que assuma a identidade do meio rural, nos seus mais diversos aspectos. O PRONERA tem concepção no sentido de trabalhar com estas especificidades (INEP/ I PNERA 2004).
\end{abstract}

Os Movimentos Sociais Campesinos, em suas práticas educativas, têm construindo conhecimento pautado na emancipação, na organização e fortalecimento da luta pela terra, por mudanças nas estruturas políticas e econômicas. Assim, segundo Jesus (2004):

Educação do Campo é um conceito que não se fecha nele mesmo, pois incorpora a própria dinâmica dos movimentos sociais do campo e intelectuais que se dedicam à questão agrária brasileira, aos problemas da exclusão social, da distribuição desigual da terra e da renda aos problemas da soberania alimentar, das patentes, entre outros. Este conceito se funda a uma intencionalidade: a busca de alternativas a um paradigma agrário capitalista 
imposto durante décadas em nosso país. Esse paradigma que procurou destruir o campo como território, tratou as pessoas como improdutivas porque não produzem para a exportação ou agronegócio e desqualificou os conhecimentos e saberes dos que vivem no campo como atrasados, porque não funcionam na mesma lógica racionalizante de expropriação e extorsão dos conhecimentos para acúmulo de poucos em detrimento de muitos. (JESUS, 2004, p: 113).

A defesa de uma educação do campo tem como sustentação o reconhecimento de uma realidade de trabalhadores e trabalhadoras do campo que têm resistido para continuar produzindo e vivendo no campo, bem como o entendimento de que esta realidade precisa ser alterada. Por isso, o projeto educacional pautado pelos Movimentos Campesinos está associado a um projeto político de transformação social, no sentido atribuído por Mészáros (2005):

\begin{abstract}
A nossa tarefa educacional é, simultaneamente, a tarefa de uma transformação social, ampla e emancipadora. Nenhuma das duas pode ser posta à frente da outra. Elas são inseparáveis. A transformação social emancipadora radical requerida é inconcebível sem uma concreta e ativa contribuição da Educação e trabalho: reflexões em torno dos movimentos sociais do campo educação no seu sentido amplo (...). E vice-versa: a educação não pode funcionar suspensa no ar. Ela pode e deve ser articulada adequadamente e redefinida constantemente no seu inter-relacionamento dialético com as condições cambiantes e as necessidades da transformação social emancipadora e progressiva em curso. (MÉSZÁRIOS, 2005, p. 76).
\end{abstract}

O conceito de Educação do Campo, conforme colocado anteriormente por Jesus (2004), é um conceito que não se fecha nele mesmo, pois incorpora a própria dinâmica dos Movimentos Sociais Campesinos, traz a importância de debater e compreender as discussões sobre a questão agrária, como também das transformações estruturais da mesma. Nesse sentido, conforme analisou Carvalho (2015), a Educação do Campo vai muito além do processo de aprender a ler e escrever, é importante fazer com que o aluno e aluna sejam levados a pensar no seu papel social e na sua participação no mesmo. Por isso, a sala de aula tem que ser um espaço para o aluno refletir sobre a sua participação nas lutas, nas conquistas, ou seja, em toda a trajetória dos Movimentos.

Nesse sentido, a sua prática deve ser concretizada por intervenções pedagógicas que façam emergir as diferenças, as intencionalidades, os valores individuais e sociais e a unidade entre os sujeitos, a fim de possibilitar a criação de uma cultura de resistência e de superação. Por isso, os Movimentos campesinos, ao falar de Educação, trazem uma concepção de educação fundamentada em princípios filosóficos e pedagógicos, que extrapola a sala de aula, mas também pensa a partir dela. 
A Educação do Campo se configura enquanto um processo em construção, voltando-se, portanto, para fortalecimento da identidade camponesa, bem como para a afirmação do campo enquanto espaço de trabalho e de vida. Nesse sentido, o PRONERA é um dos agentes fortalecedores dessa proposta. Conforme já foi colocado, inicialmente tinha como proposta a redução da taxa de analfabetismo, hoje já possui cursos de formação de professores nos níveis superior e médio, diversos cursos de graduação e um mestrado acadêmico, habilitação técnico-profissional, para jovens e adultos, seguindo a linha de interesse para a formação na área de produção, agropecuária, entre outras.

Conforme já mencionamos, o PRONERA constitui-se de uma parceria entre o Instituto Nacional de Colonização e Reforma Agrária - INCRA, as Universidades e os Movimentos Social e Sindical do campo. Cada parceiro envolvido segue uma linha para possibilitar o funcionamento do programa. As Universidades se responsabilizam pela mediação entre o INCRA e os Movimentos Sociais, bem como a elaboração dos projetos; acompanhamento pedagógico nas áreas e por fim são responsáveis pela gestão dos recursos financeiros do programa. Os Movimentos Sociais têm o papel de mobilização das comunidades, acompanhamento das atividades e a aplicação dos recursos. As Superintendências Regionais do INCRA fazem a articulação entre os parceiros, através da observação e identificação das necessidades educacionais das áreas, bem como, a verificação a aplicação dos recursos.

A Educação do Campo como um paradigma em construção busca através de sua inserção no campesinato, contribuir com o fortalecimento do território camponês. Nesse sentido, a Educação do Campo pode ser entendida como um projeto educacional que leva em consideração a vivência dos camponeses. Suas práticas sociais fortalecem o sentido de identidade e pertencimento no meio em que vivem. Nesse entendimento é que se vai construindo Segundo Oliveira (2010) o paradigma da Educação do Campo:

\footnotetext{
O paradigma da Educação do Campo busca reunir o conhecimento da classe trabalhadora no campo e a cultura camponesa, para construir uma identidade que lhe é própria. Os seus ideólogos são os próprios sujeitos dessa educação, que trabalham e vivem no campo e seus processos de formação pelo trabalho, pela produção de cultura, pelas lutas sociais, que por muitos anos foi tratado de modo preconceituoso, discriminatório (OLIVEIRA, 2010, p. 77).
}

Essa luta refere-se a um novo projeto construído coletivamente pelos agricultores e agricultoras, que vão forjando no campo um novo ideal de educação e de escola. Como 
reflete Silva (2013, p. 33), "essa concepção de Educação do Campo diz respeito, portanto, à classe trabalhadora do campo":

Uma educação popular, na perspectiva desses sujeitos e efetivada por eles; desenvolvida no campo e afirmadora do modo de vida camponês; vinculada a um projeto de campo que represente os interesses da classe trabalhadora camponesa e se paute num modo de produção e modelo de desenvolvimento não capitalista. (p. 33).

Assim, pensar uma educação voltada para o homem e a mulher do campo é essencial, sobretudo por corresponder a uma tentativa de pagar a dívida histórica que o país tem para com esses sujeitos. Nesse entendimento, refletimos sobre o fato de que não pode ser qualquer proposta de educação, na perspectiva do MST é necessário que seja,

[...] uma educação voltada para a realidade do meio rural é aquela que ajuda a solucionar os problemas que vão aparecendo no dia a dia dos assentamentos e acampamentos, que forma os trabalhadores e as trabalhadoras para o trabalho no meio rural, ajudando a construir reais alternativas de permanência no campo e de melhor qualidade de vida para esta população (MST, 1996, p.07-08).

Foi no sentido de contribuir com esse processo que a Universidade Estadual Vale do Acaraú começou, logo após a criação e aprovação do PRONERA, uma parceria firmada entre o INCRA - Instituto Nacional de Colonização e Reforma Agrária, MST Movimento dos Sem-Terra, e FETRAECE - Federação dos Trabalhadores Rurais do Estado do Ceará. Inicialmente coma Alfabetização de Jovens e Adultos ${ }^{1}$ e mais recente, com um Curso de Segunda Licenciatura, conforme veremos no item 2

\section{As experiências do PRONERA na UVA - Alfabetização de Jovens e adultos}

O primeiro curso do PRONERA na UVA aconteceu entre os anos 1998 e 2002, com um projeto de Educação de Jovens e adultos, nesse momento, segundo Diniz (2002/2003), foram beneficiados 42 Assentamentos de Reforma Agrária, o que representava $21 \%$ de Assentamentos do Estado do Ceará. Estes estavam localizados em Sobral, Barroquinha, Camocim, Cariré, Granja, Forquilha, Massapê, Senador Sá, Santana do Acaraú, Santa Quitéria e Tianguá

Ainda segundo Diniz (2002/2003 p. 117) foi formada 73 turmas com 20 alunos por sala com um tempo total de alfabetização de $560 \mathrm{~h} / \mathrm{a}$. Para conciliar as aulas com as atividades diárias dos alunos e alunas, foram ministradas duas hora/aula todos os dias da semana, totalizando 14 meses de aula. As aulas foram ministradas das 19:00 às 21:00 horas. 
O PRONERA/SOBRAL tinha como meta a alfabetização de 1.460 jovens e adultos nas áreas de assentamento de reforma agrária da Zona Norte do estado do Ceará. Previa também a capacitação de 73 assentados(as), que depois de treinados pelos professores(as) universitários(as), assumiram, ao lado de suas atividades agrícolas, a tarefa de alfabetizadores(as). Estes receberam o nome de Monitores. Outra meta do projeto era escolarização desses Monitores, que foi viabilizada em parceria com o Centro de Educação de Jovens e Adultos CEJA/Sobral. (DINIZ, 2002/2003, p. 116).

Seguindo a proposta pedagógica da Educação do Campo o PRONERA/UVA voltou-se para a realidade dos assentamentos e da questão agrária brasileira, buscando resgatar a cidadania dos trabalhadores e trabalhadoras do campo. Nesta proposta, a aprendizagem escolar valorizou a história de cada educando e educanda bem como a história da comunidade e das lutas no campo, ou seja, os processos educativos passaram pelo conjunto de experiências e vivências que o agricultor e agricultora tiveram ao longo de sua vida. Vale ainda ressaltar que, nos espaços educativos, também eram considerados outros espaços, como marchas, reuniões, congressos, atividades ligadas à formação no MST, como lugares onde se desenvolve o processo educacional.

A preocupação era que o educando e educanda tivesse como fonte de aprendizagem o seu próprio ambiente de trabalho e vida como referência, de modo que, a aprendizagem se fizesse de forma prazerosa, com um modelo diferente daquele que há muito tempo excluiu esse indivíduo da escola. Por isso, nos informou Diniz (2002/2003), que as atividades pedagógicas foram desenvolvidas integrando-se às necessidades identificadas nos assentamentos, vinculando a escola à cultura que se produz por meio das relações sociais mediadas pelo trabalho na terra:

Para atingir esse objetivo, utilizamos temas geradores que foram trabalhados através de vários recursos didáticos, como, por exemplo: teatro de bonecos, música, mímica, palestra, jogos, recortes de jornais locais e do MST, como também rótulos dos produtos utilizados nos assentamentos. (DINIZ, p. 116 2012/2003).

Nesse sentido, ainda segundo Diniz (2912/2013), os conteúdos trabalhados foram articulados com sua realidade, lendo e escrevendo sobre suas vidas e fazendo uma leitura crítica do mundo que os rodeia no sentido social, político e econômico. Desta forma, os alunos e alunas se percebem não como mais um número, mas como sujeitos sociais que trazem histórias e que têm diferenças. "Ninguém aprende nada fora de um determinado contexto e nem aprende por aprender. As pessoas aprendem inseridas numa complexa rede de ações e relações, e aprendem para atuar nesta rede". (CALDART, p 115, 1997). 
Outra característa metodológica a destacar nessa proposta dos cursos oferecidos por esse Programa refere-se a sua metodologia, que é baseada na Pedagogia da Alternância ${ }^{2}$. Essa concepção pedagógica segundo Vendrine (2007) foi trazida para o Brasil na década de 1960, com as experiências de formação em alternância das Escolas Famílias Agrícolas (EFAs) e das Casas Familiares Rurais (CFRs). Constitui-se num processo de formação que articula as atividades pedagógicas com a realidade cotidiana dos(as) educandos(as), ou seja, há uma articulação de períodos de vivência na sala de aula e no trabalho, resultando no Tempo Escola ${ }^{3}$ e Tempo Comunidade ${ }^{4}$.

Esses alunos e alunas são sujeitos que inclusos em relações camponesas, que envolve o trabalho doméstico ou familiar, ou seja, são, ao mesmo tempo, estudantes e trabalhadores. Logo, se faz necessário a construção de uma educação que seja compatível com a territorialidade desses camponeses-estudantes e que auxiliem na sua luta pela/na terra e no seu processo de manutenção/reprodução

Conforme colocado, inicialmente surgiu a demanda por alfabetização de jovens e adultos, hoje o Programa Nacional de Educação na Reforma Agrária (PRONERA) apresenta uma grande representatividade nas suas ações em assentamentos e acampamentos.

\section{Curso de Segunda Licenciatura}

A conquista do PRONERA, mesmo compreendida como ferramenta a mais para Educação do Campo, por si só não garantiu solucionar os problemas relacionados com a intensa taxa de analfabetismo no campo.

Nesse sentido, surge a necessidade de criação de escolas públicas de ensino médio nos Assentamentos de Reforma Agrária, combinado com a luta pela preservação de suas escolas de ensino fundamental e combinada, também, com a luta já travada pelo direito à educação em todos os níveis. Essa luta conquistou, em parceria com várias Universidades Públicas do Brasil em diversos estados, cursos de graduação que têm permitido a formação da juventude para que permaneçam no campo exercendo diversas atividades profissionais

No Ceará, o MST faz uma grande jornada de luta que compreendeu a realização de marchas, ocupações, reuniões e mobilizações envolvendo diversas famílias que se posicionaram frente ao governo, no anseio de garantir o direito ao acesso à educação aos 
jovens camponeses. Esses eram jovens em idade escolar e que se sujeitavam às mais perversas condições para chegar à escola localizada na cidade. É importante destacar que são muitos os fatores que justificam a luta por educação do Campo no Ceará, passando desde a precarização educativa que a juventude camponesa, residentes nessas áreas, estava sujeita como, por exemplo, a falta de transporte o que ocasionava longas distâncias percorridas até a escola da cidade, bem como, a ausência de merenda escolar. Cita-se ainda o preconceito que estes sujeitos sofrem por serem provenientes do campo. Em adição, cita-se o fato de que não existiam, no estado do Ceará, escolas de Ensino Médio que, de fato, atendessem aos interesses dos agricultores e agricultoras.

O fruto dessas lutas, travada no seio do Movimento dos Sem Terra - MST, levou à conquista da construção de oito Escolas do Campo de Nível Médio, em Áreas de Assentamentos de Reforma Agrária, conforme ilustrado no quadro 1.

Quadro 1: Escolas de Nível Médio do Campo em funcionamento no CE

\begin{tabular}{|cccc|}
\hline MUNICÍPIO & ASSENTAMENTO & ESCOLA & $\begin{array}{c}\text { ANO DE } \\
\text { CONSTRUÇÃo }\end{array}$ \\
\hline Madalena & 25 de Maio & EEM João dos Santos & 2010 \\
\hline Itapipoca & Maceió & $\begin{array}{c}\text { EEM Maria Nazaré de } \\
\text { Sousa }\end{array}$ & 2010 \\
\hline Monsenhor Tabosa & Santana & $\begin{array}{c}\text { EEM Florestan } \\
\text { Fernandes }\end{array}$ & 2010 \\
\hline Itarema & Lagoa do Mineiro & $\begin{array}{c}\text { EEM Francisco Araújo } \\
\text { Barros }\end{array}$ & 2010 \\
\hline Jaguaretama & Pedra e Cal & $\begin{array}{c}\text { EEM Pe. José Augusto } \\
\text { Régis Alves }\end{array}$ & 2010 \\
\hline Canindé & Santana da Cal & EEM Patativa do Assaré & 2016 \\
\hline Santana do Acaraú & Bonfim Conceição & $\begin{array}{c}\text { EEM José Fideles de } \\
\text { Moura }\end{array}$ & 2016 \\
\hline Ocara & Antônio Conselheiro & $\begin{array}{c}\text { EEM Francisca Pinto } \\
\text { dos Santos }\end{array}$ & 2017 \\
\hline
\end{tabular}

Fonte: Elaborado DINZ, 2018.

Com a conquista dessas escolas, outros desafios foram aparecendo, tais como a carência de professores(as) para atender as demandas dessas escolas. Conforme foi colocado no Projeto Político Pedagógico do Curso (2003), a conquista das escolas do campo, evidenciou outros desafios, uma demanda de educadores e educadoras com formação para as áreas específicas do conhecimento, habilitados para o segundo segmento do ensino fundamental e médio, bem como uma grande lacuna na formação inicial desses profissionais para o trabalho docente no campo nos marcos da Educação do 
Campo.

Considerando-se que, com a implantação das escolas do campo surgiu a emergência e exigência da formação dos(as) professores(as) com habilitação adequada para lecionarem utilizando a proposta pedagógica da Educação do Campo, com uma atuação que valorize o lugar, o trabalho, os costumes e tradições camponesas, bem como a luta pela Reforma Agrária. Assim sendo, a UVA em parceria com o INCRA, passou a oferecer o Curso de Segunda Licenciatura nas Áreas de Ciências Humanas e Sociais: Licenciatura em Geografia; Licenciatura em História; com o objetivo de habilitar professores e professoras e outros profissionais da educação com formação inicial em pedagogia ou em outra licenciatura que estivessem morando em áreas de Assentamentos de Reforma Agrária. Com uma segunda licenciatura, ampliar-se-iam as possibilidades de atuação na educação básica, em especial no segundo segmento do Ensino Fundamental e no Ensino Médio nas referidas áreas.

\footnotetext{
Diante disso, e considerando a possibilidade criada com o Parecer CNE/CP $\mathrm{N}^{\circ}$ 08/2008 e a Resolução CNE/CP n ${ }^{\circ}$ 01/2009, que estabelecem diretrizes para a implantação do Programa Emergencial de Segunda Licenciatura para Professores em Exercício na Educação Básica Pública, apresentamos a presente proposta para realização de cursos de Segunda Licenciatura nas áreas de concentração do conhecimento, com ênfase em Educação do Campo e Questão Agrária. (PPP, 2013, p. 8).
}

Assim sendo, o Curso teve duração de dois anos, tendo começado a ser executado em 2015, tendo sido finalizado em 2017. A pretensão inicial foi formar duas (02) turmas com um total de 100 Licenciados em Ciências Humanas e Sociais, sendo conferido o grau para 50 formandos em Licenciatura Plena em Geografia; 50 formandos em Licenciatura Plena em História; sendo $100 \%$ das vagas para a região Nordeste. Mas devido a vários desafios surgidos ao longo do curso terminamos com um total de 63 alunos e alunas.

Vale ressaltar que os alunos e alunas que cursaram a Segunda Licenciatura em História e a Segunda Licenciatura em Geografia, são alunos dos Assentamentos de Reforma Agrária, conquistados através de muita luta, onde muitas vidas tombaram para outros agricultores e agricultoras pudessem ter acesso à terra de trabalho.

Esse Curso foi criado com a perspectiva de contribuir com a formação de educadores e educadoras do campo nas áreas específicas do conhecimento, fortalecendo, com isso, as condições objetivas para elevação da escolaridade nos Assentamentos de Reforma Agrária. Com uma segunda licenciatura, voltada para os sujeitos do campo, acreditamos que possibilitará maior permanência dos educadores e educadora na escola, 
condição importante para implementação de um currículo adequado à realidade do campo melhorando as condições para o enfrentamento dos seus desafios.

O currículo do Curso de segunda Licenciatura foi organizado em áreas de conhecimento das Ciências Humanas e Sociais com habilitação em Geografia e História, podendo os estudantes optarem para serem habilitados em uma dessas áreas. Segundo o seu Projeto Político Pedagógico (2013), a organização curricular apresentou uma carga horária total de 1.305 horas/aula, com 87 créditos integralizados em quatro períodos/módulos distribuídos entre o Tempo Universidade e o Tempo Comunidade. Nestes períodos intensivos, compreendidos como Tempo Universidade, com uma carga horária de $70 \%$ do Curso, os estudantes tiveram formação presencial no campus universitário da UVA. O Tempo Comunidade, com carga horária 30\% do Curso, foi destinado à pesquisa e as práticas e vivências na comunidade, denominação para os estágios supervisionados, como também para estudos e elaboração do Trabalho de Conclusão de Curso - TCC.

Neste sentido, tanto a formalização da demanda como a construção da matriz curricular se deram em diálogo com o Movimento dos Sem Terra -MST, as Secretarias Municipais da região, a Secretaria da Educação do Ceará -SEDUC e o Comitê Executivo da Educação do Campo do Estado do Ceará:

Desta forma o curso pretende constituir-se uma construção coletiva de formação de educadores para as escolas do campo contribuindo efetivamente para a superação das históricas desigualdades educacionais vividas pelos povos que o habitam e simultaneamente corroborando para o esforço de fortalecimento da Educação do Campo, do sistema público de educação na perspectiva da melhoria e qualidade do processo de ensino-aprendizagem no Estado do Ceará, da inclusão social enquanto direito fundamental que é a educação, garantido na Constituição Federal de 1988. (PPP, 2013, p. 10).

Ainda segundo o Projeto Político Pedagógico (2013), a estrutura curricular deve articular a estrutura da Formação Pedagógica para a Educação do Campo e a estrutura da Formação Específica nos conteúdos da área ou disciplina para a qual estará sendo licenciado. Portanto, conforme a Resolução CNE/CP n 2/1997, a proposta pedagógica do curso constou de:

a) Núcleo Contextual: visa à compreensão dos processos de ensino e aprendizagem referidos à prática na escola, as relações que se passam no seu interior, com seus participantes, bem como as suas relações, como instituição, no contexto imediato e no contexto geral onde está inserida. Têm-se como princípio a Questão Agrária e a Educação do Campo integradas as atividades do curso que objetivarão a formação de uma teia de interações através de 
vivências didáticas em sala de aula, ação docente supervisionada, seminários temáticos, encontros pedagógicos, oficinas e ações comunitárias.

b) Núcleo Estrutural abordar um corpo de conhecimentos curriculares, sua organização sequencial, avaliação e integração com outras disciplinas, os métodos adequados ao desenvolvimento do conhecimento em pauta, bem como sua adequação ao processo de ensino e aprendizagem. Nesse sentido, consideram-se: flexibilidade na compreensão e universalização do conhecimento trabalhado em aulas, seminários e estudos orientados; interdisciplinaridade na produção e socialização do conhecimento; alternância de estudos das áreas gerais de formação do professor com áreas específicas; mediação da teoria e prática pedagógicas feita pelos educadores/educandos, integrando formação acadêmica com formação continuada; com espaço para a reflexão, o diálogo e a tomada de decisões relativas à realização do curso; qualidade nos procedimentos didático-metodológicos, buscando uma ação docente efetiva.

c) Núcleo Integrador, centrar nos problemas concretos enfrentados pelos educadores/educandos da educação básica das escolas do campo, com vistas ao planejamento e organização da ação docente, problematizando, a partir de diferentes perspectivas teóricas das ciências humanas e sociais,com a participação articulada dos educadores/educandos das várias disciplinas do curso. (PPP, 2013, p. 19-20).

Ainda de acordo com o Projeto Político Pedagógico (2013), os Núcleos: Contextual, Estrutural e Integrador no Curso de Segunda Licenciatura em Ciências Humanas e Sociais da UVA se estruturaram em: 01 (um) Seminário Introdutório que compõe a Base Curricular Comum, Base Curricular específica para cada habilitação e Atividades Integradoras. Essa estrutura foi desenvolvida em quatro períodos/módulos, em Tempo Universidade nos meses de janeiro e julho (2015 e 2017) e Tempo Comunidades (fevereiro a junho e agosto a dezembro). A carga horária de $1.305 \mathrm{~h} / \mathrm{a}$ foi assim distribuída ao longo do curso: Esse fato é ilustrado pelo quadro 2.

Quadro 2 - Carga horária de cada módulo

\begin{tabular}{cc}
\hline Proposta & Carga horária \\
\hline Base Curricular Comum* & $390 \mathrm{~h} / \mathrm{a}$ \\
Tempo Comunidade & $330 \mathrm{~h} / \mathrm{a}$ \\
Base Curricular Específica - Geografia* & $585 \mathrm{~h} / \mathrm{a}$ \\
\hline Base Curricular Específica - História* & $585 \mathrm{~h} / \mathrm{a}$ \\
\hline
\end{tabular}

Fonte: Projeto político pedagógico (2013).

Para participarem do processo de seleção do curso, os candidatos(as) foram mobilizados(as) pelo MST e as organizações locais onde estavam inseridos, levando em conta a sua participação na vida da comunidade, no engajamento nos movimentos sociais e em processos de educação, formação e organização nos Assentamentos de Reforma Agrária. Nessa perspectiva, após a organização da demanda feita pelo Movimento, houve 
a inscrição dos candidatos para a realização da seleção pela universidade.

O processo seletivo foi de caráter classificatório e de responsabilidade de uma comissão dos professores dos cursos envolvidos (Geografia e História da UVA), sendo avaliados os educadores/educandos através de um memorial de sua formação e ação docente. Desta forma a escolha do curso foi feita no momento da inscrição, não podendo o mesmo aluno e aluna cursar simultaneamente os dois cursos.

\section{Considerações Finais}

A educação do campo tem motivado, nas duas últimas décadas, debates, pesquisas, políticas públicas e ações de movimentos sociais organizados. A partir do final dos anos 1990, o Movimento dos Sem Terra - MST, junto com outras organizações sociais, engajou-se num movimento nacional por uma educação do campo, com grande mobilização e forte pressão social. Tal mobilização foi capaz, inclusive, de pressionar o Estado por políticas públicas para o campo. Além disso, mudou o foco teórico do debate, com a conceituação Educação do Campo em contraposição à Educação Rural, avançando na direção de uma educação em sintonia com as populações que vivem e trabalham no campo.

As experiências da Educação do Campo através do PRONERA, e mais especificamente as experiências vividas na UVA, nos leva a concluir, em primeiro lugar, que a Educação do Campo não é um ato isolado, mas coletivo. Em segundo lugar, concluise que a educação na perspectiva da transformação social deve estar associada com formas alternativas e coletivas de produção da vida, na direção da construção do que Harvey (2004) chama de "espaços de esperança".

Seu impacto social tem um grande alcance, não somente para os agricultores e agricultoras que fizeram os cursos, mas para os(as) jovens que moram nas áreas de Assentamento de Reforma Agrária pois, terão outras possibilidades de participar da criação de condições para permanência no campo com uma vida digna. Já os agricultores e agricultoras que fizeram esse curso, foram selecionados(as) não somente como professores e professoras, mas também para responderam por coordenações e direção de algumas escolas.

Outro fator que devemos levar em consideração é que os(as) jovens que estão estudando nas escolas do campo criam as condições de permanência no campo com vida 
digna e passam a construir seus sonhos de vida em suas comunidades, pois a Educação do Campo traz consigo uma série de valores e práticas que buscam uma valorização do modo de vida camponês, estando assim dentro do paradigma de interpretação da revalorização do campo. Assim sendo, são vários jovens que deixam de vir engrossar as fileiras nas periferias das cidades, sem condições de trabalhos e fadados a serem criminalizados e eliminados pelas forças repressoras. Podemos afirmar que a Educação do Campo é uma conquista e ao mesmo tempo uma bandeira de luta da classe camponesa.

Para finalizar, menciona-se a atual situação conjuntural que passa o pais após o golpe parlamentar, judiciário e midiático. Um golpe representado pelos setores mais conservadores, e apoiados pelos interesses do capital financeiro, impulsionadas por forças que desejam recuperar a direção do Estado para o bloco oligárquico-rentista, o que põe em riso não somente as conquistas dos camponeses e camponesas ao longo da história, mas a própria democracia brasileira.

A primeira ofensiva contra os camponeses e as camponesas foi a extinção do Ministério do Desenvolvimento Agrário, este era o ministério responsável pelas políticas direcionadas à agricultura camponesa na qual estava inserido o PRONERA. Consideramos um grande retrocesso, pois a extinção do referido Ministério representa cortes de recursos em Políticas Públicas não somente garantidoras de direitos, mas, sobretudo, censura nos instrumentos de transformação, a exemplo do que tem se configurado a luta pela Política Pública de Educação do Campo.

Nesse momento, conforme nos ensinou Paulo Freire, precisamos denunciar e lutar contra todo mecanismo e todos os indivíduos que sujeitam o ser humano às mais bárbaras, violentas e opressoras condições de dominação, e instituem os mecanismos políticos necessários para a consolidação de seu poder.

Sabemos que contra a histórica atrocidade que existem por parte do Estado capitalista através de seu aparelho repressor, só nos resta à luta e a organização dos sujeitos historicamente oprimidos e expropriados. Com o Congresso Nacional cada vez mais reacionário, fica mais difícil realizar as reformas que a sociedade precisa, principalmente a Reforma Agrária, muito menos a Reforma Agrária almejada pelo MST que é a Reforma Agrária Popular, articulada com infra-estrutura básica, com acesso a uma educação de qualidade, saúde e todas as condições que propiciem o desenvolvimento das famílias, não somente no campo mais também na cidade. 
É neste sentido que acreditamos que outro mundo é necessário e possível. Esse novo mundo já está sendo construído em vários lugares por distintos grupos, a partir de seus particulares métodos de trabalho e critérios organizativos. Acreditamos que a educação como ato de libertação, é o elemento central do fazer educativo do Movimento dos Trabalhadores Rurais Sem Terra, dos grupos que lutam pela Educação Indígena, e por Escolas para Famílias Agrícolas, assim como a educação de jovens e adultos. Falamos, enfim, em educação popular.

\section{Notas}

\footnotetext{
${ }^{1}$ Sobre essa primeira experiência ver artigo publicado na Revista da Casa da Geografia de Sobral, v. 4/5, p. 115-129, 2002/2003. O Artigo tem o seguinte título: PRONERA/SOBRAL: RELATOS DE UMA EXPERIÊNCIA de autoria de Aldiva Sales Diniz.

${ }^{2}$ A alternância é uma estratégia que visa favorecer a formação do indivíduo num ambiente propício à reflexão de suas próprias experiências. Para alcançar esse propósito, ela engloba dois períodos de formação vividos em tempo integral: um período de estudo na escola, seguido de outro período no trabalho. (PESSOTTI, p. 11 1975).

${ }^{3}$ Momento de estudos que ocorrem na sala de aula.

${ }^{4}$ Momento em que os alunos se voltam para seus espaços de vivência.
}

\section{Referências}

ARROYO, Miguel Gonzalez; CALDART, Roseli Salete; MOLINA; Mônica Castagna (orgs). Por uma Educação do Campo. 3.ed. - Petrópolis, RJ: Vozes, 2008.

CALDART, Roseli Salete. Escola é mais do que escola na Pedagogia do Movimento Sem Terra. Universidade Federal do Rio Grande do Sul, 1999 (Edição: Petrópolis, Vozes, janeiro de 2000).

CALDART, Roseli.Salete. Elementos para a construção de um projeto político e pedagógico da educação do campo. In: MOLINA, M.C.; JESUS, S.M.S.A. Por uma educação do campo: contribuições para a construção de um projeto de educação do campo. Brasília, DF: Articulação Nacional "Por uma educação do campo", 2004, p. 13-52.

2004.

Pedagogia do Movimento Sem Terra. São Paulo: Expressão Popular,

CARVALHO, Jozeisa Gama de. A gestão do PRONERA no estado de Sergipe: Uma análise do Curso de Pedagogia no período 2010 a 2013. In: MARTINS, Maria de Fátima Almeida e RODRIGUES, Sonia da Silva (Org.). PRONERA: Experiências de Gestão de uma Política Pública. São Paulo: COMPACTA: Gráfica e Editora, 2015.

DAMASCENO, Cosma dos Santos. Contribuições e Desafios da Escola do Campo Francisco Araújo Barros para construção do projeto de agricultura camponesa do 
MST - Ceará. (Dissertação de Mestrado) Programa de Mestrado Profissional em Agroecossistemas da Universidade Federal de Santa Catarina. Florianópolis - SC, 2015.

DINIZ, Aldiva Sales. PRONERA/Sobral: Relatos de uma Experiência. Revista da Casa da Geografia de Sobral, Sobral, v. 4/5, p. 115-129, 2002/2003.

DINIZ, Aldiva Sales Diniz. OLIVEIRA, Adeliane Vieira de. NASCIMENTO, Cícero Danilo Gomes do. O saber popular no chão da escola: o inventário da realidade como instrumento teórico/ prático da educação do campo no ceará. Anais do IV EREPEG: Formação docente e avaliação em Geografia. Grato Ceará, 2018.

HARVEY David. Espaços de esperança. São Paulo: Edições Loyola. 2004.

IASI, Mauro Luiz. Ensaios sobre consciência e emancipação. São Paulo: Expressão Popular, 2011.

INEPIMEC. I Pesquisa Nacional da Educação na Reforma Agrária (PNERA). Disponível em: www.inep.gov.br. Acesso em 16/09/2017.

KOLLING, Edgar. José. [et. al] [orgs.] Por uma educação básica do campo Memória. Brasília: Educação, UNB, 1999.

FREIRE, Paulo. Pedagogia da autonomia: saberes necessários à prática educativa. 30 ed. São Paulo: Paz e Terra, 2004.

FREIRE, Paulo. Educação e Mudança. 34. Ed. - São Paulo: Paz e Terra, 2011.

FREIRE, Paulo. Pedagogia do oprimido. Rio de Janeiro: Paz e Terra, 1985. (15a . ed.).

MESZÁROS, I. A educação para além do capital. São Paulo: Boitempo, 2005.

MOLINA Mônica C; ROCHA Maria Isabel Antunes. Educação do Campo: história, práticas e desafios no âmbito das políticas de formação de educadores - reflexões sobre o PRONERA e o PROCAMPO. Revista Reflexão e Ação, Santa Cruz do Sul, v.22, n.2, p. 220 - 2 53, jul./dez.2014 Disponível em:

<http://online.unisc.br/seer/index.php/reflex/index>, acessada no dia 16/09/2017.

MORIGI, Valter. Escola do MST uma utopia em construção. Porto Alegre - RS, Editora Mediação, 2003.

OLIVEIRA Adeliane Vieira de; SALES Telma Bessa; DINIZ Aldiva Sales.

PRONERA/UVA: Narrativas sobre a formação de professores. Rev. Geosaberes, Fortaleza, v. 8, n. 16, p. 106-120, set./dez. 2017.

SOUZA, Rubneuza Leandro de. Educação do campo: análise das reivindicações dos trabalhadores do campo e das propostas dos governos de Luiz Inácio Lula da Silva e Dilma Rousseff. Rev. Tamoios, São Gonçalo (RJ), ano 09, n. 2, pags.5 - 28, jul/dez. 2013. 
SANTOS, Rejane Cristina de Abreu. A experiência do PRONERA no assentamento paz na terra: considerações sobre a educação do campo e a relação campo cidade. SANTOS, Clarice Aparecida. (org). Balanço Político e Linhas de Ação do PRONERA Rumo aos 10 Anos. Por uma Educação do Campo. Campo-PoliticasPublicas-Educação. Brasília: Incra; MDA, 2008.

UNIVERSIDADE ESTADUAL VALE DO ACARAÚ - UVA. Programa Segunda Licenciatura nas áreas de Ciências Humanas e Sociais, com Ênfase em Educação do Campo e Questão Agrária. Sobral/ Ce. 2013.

VENDRAMINI, Célia Regina. Educação e trabalho: reflexões em torno dos movimentos sociais do campo. Cad. Cedes, Campinas, vol. 27, n. 72, p. 121-135, maio/ago. 2007. Disponível em <http://www.cedes.unicamp.br> acessada em 18/09/2017.

Recebido em 11/04/2019.

Aceito para publicação em 17/06/2019. 